\title{
Distribution pattern of free living nematode communities in the eight Mekong estuaries by seasonal factor
}

\author{
Sụ phân bố của quần xã tuyến trùng sống tụ do ở 8 cưa sông Mekong theo mùa \\ Research article
}

Ngo, Xuan Quang ${ }^{*}$; Nguyen, Ngoc Chau ${ }^{2}$; Nguyen, Dinh $\mathrm{Tu}^{2}$; Pham, Van Lam ${ }^{3}$; Vanreusel, $\mathrm{Ann}^{4}$

${ }^{1}$ Institute of Tropical Biology, Vietnam Academy of Science and Technology, 85 Tran Quoc Toan Street, District 3, Ho Chi Minh City, Vietnam; ${ }^{2}$ Institute of Ecology and Biological Resources, Vietnam Academy of Science and Technology, Vietnam; ${ }^{3}$ Institute of Environmental Technology, Vietnam Academy of Science and Technology, Vietnam; ${ }^{4}$ Ghent University, Biology Department, Marine Biology Section, Krijgslaan 281/S8, B-9000, Gent, Belgium

\begin{abstract}
The temporal variation of nematode communities in eight mouth stations of the Mekong River system was investigated in order to compare the change between the dry and the wet season. The nematode data was analysed by multivariate techniques such as SIMPROF, MDS, ANOSIM and SIMPER in the software PRIMER v.6 - PERMANOVA. Our results showed that average dissimilarity between seasons of the nematode communities in each station was high. Seasonal factor did not affect strongly their distribution pattern. Dominant genera Desmodora and Oncholaimellus usually occurred in the sand stations and Parodontophora and Halalaimus were characteristic for the silty group in both seasons. The spatial variations in this estuarine area have an influence that is larger than seasonal factors.
\end{abstract}

Sự phân bố theo thời gian của quần xã tuyến trùng sống tư do vùng cửa sông Mekong được nghiên cứu nhằm đánh giá sự khác biệt của chúng trong mùa mua và mùa khô. Dũ liệu của tuyến trùng được xử lý và phân tích đa biến nhu SIMPROF, MDS, ANOSIM và SIMPER bằng phần mềm PRIMER v.6-PERMANOVA. Kết quả nghiên cúu cho thấy sụ khác biệt theo mùa trong quần xã tuyến trùng tại mỗi điểm là khá lớn nhưng yếu tố mùa không ảnh huởng gì tới mô hình phân bố của chúng. Một số giống ưu thế trong nền đáy cát nhu Desmodora and Oncholaimellus trong khi đó Parodontophora và Halalaimus thich nghi nền bùn sét phù sa vẫn hiễn diện trong cả 2 mùa. Kết quả nghiên cứu cũng cho thấy sư biến động trong không gian ở đây lớn hơn sư biến động về mùa vu.

Keywords: nematode communities, seasonal factor, Mekong estuary

\section{Introduction}

Due to complicated natural conditions in the Mekong estuaries related to seasonal fluctuations, it is important to get an idea on the temporal variability of the nematode communities' structure between both seasons. In the past, the influence of seasonality on estuarine nematode was studied at different places over the world. Tietjen (1969) studied two shallow estuaries in New England and found that temperature and food are the most obvious factors explaining nematode density changes. Heip et al. (1985) noted that the seasonal cycle of nematodes could be very different from site to site according to different local environmental conditions and depending on the species composition. In 1986, Hodda and Nicholas investigated the temporal changes in littoral nematodes from the Hunter estuary reporting that there were large fluctuations in the total numbers of nematodes at the various sites throughout the year, but a consistent pattern applicable to all sites was lacking. A few nematodes, mostly epistrate feeders, each showed consistent changes in density at all sites over the year, but most nematodes including other epistratum feeders did not. The density of most species changed during the year, but these changes could not be consistently related to the seasons, and it was suggested that non-seasonal environmental changes are of greater significance. Alongi (1987) found in five Australian estuaries that the densities were not significantly different 
among estuaries, but differed seasonally (summer greater than winter). Another study of Hodda \& Nicholas (1990) on the production of meiofauna in an Australia estuary over four seasons showed that the proportion of adult males and juveniles in the population and their mean size changed from season to season.

In addition, Li and Vincx (1993) studied two fine sandy intertidal stations in the polyhaline and mesohaline zone of the Westerschelde estuary from 1983-1989. In this study, the authors found neither a difference between spring and autumn nor a significant trend over seven years but they mentioned that the instability in the estuarine habitats are mainly caused by upstream effects (mainly related to fresh water input) by the River Schelde that clearly influenced the stability of the nematode communities. So the overall conclusion of these studies is that nematode communities do differ between seasons but there is no consistent pattern observed. Therefore it is important to identify the distribution pattern of nematode communities in the eight Mekong estuaries in order to identify their temporal stability in relation to their spatial variability.

\section{Methodology}

\subsection{Study area, sampling coordinates and map}

Nematode samples were collected at the mouth of eight estuaries: Cua Tieu (ECT1), Cua Dai (ECD1), Ba Lai (EBL1), Ham Luong (EHL1), Co Chien (ECC1), Cung Hau (ECH1), Đinh An (EDA1) and Tran De (ETD1) in the wet season (September 2008) and dry season (March 2009) (Figure 1). Almost all stations were consisting of 100 percentage of sand in sediment except ETD1 and especially ECC1.

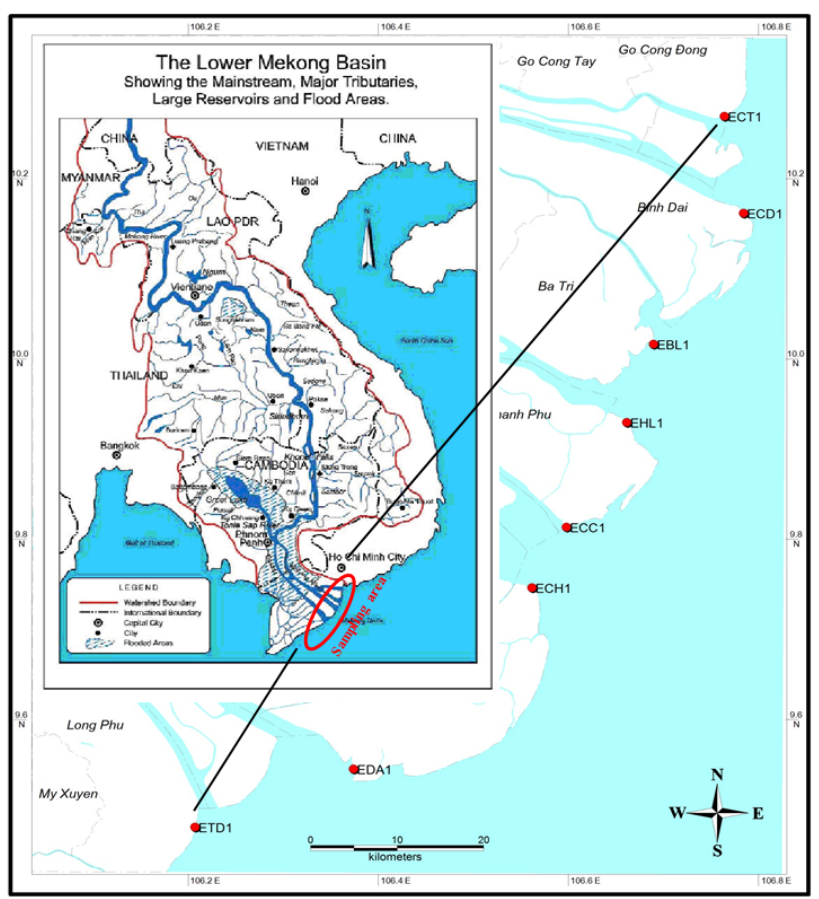

Figure 1. The sampling location at the mouths of eight Mekong estuaries in the wet and dry seasons

\subsection{Nematode samples in collection and pro- cesses}

The nematode samples were collected using cores of 3.6 $\mathrm{cm}$ diameter $\left(10 \mathrm{~cm}^{2}\right.$ surface area $)$ and $10 \mathrm{~cm}$ high. The cores were pushed down into the sediment up to $10 \mathrm{~cm}$ deep. Per station and sampling event, three replicates were taken and collected in plastic bottles. The samples were fixed in $60^{\circ} \mathrm{C}$ hot of $7 \%$ formalin solution and gently stirred. Samples were decanted and extracted at the laboratory of Marine Biology Section, Ghent University, Belgium, and the Department of Environmental Management and Technology, Institute of Tropical Biology, Vietnam. Samples were sieved and collected through 1000 $\mu \mathrm{m}$ to a $38-\mu \mathrm{m}$ mesh and extracted by the flotation technique using Ludox-TM50 (specific gravity of 1.18).

To facilitate sorting the nematodes, the samples were stained with $1 \%$ solution of Rose Bengal. The nematodes were identified by using a high magnification microscope Leica (Type III) and Olympus BX41 using different documents such as Platt and Warwick (1983), Platt and Warwick (1988) and Warwick et al. (1998).

\subsection{Data analyses}

Nematode data from identification were analyzed by using Microsoft Excel and software PRIMER v.6 PERMANOVA. To perform multivariate techniques, all data was transformed with $\log (\mathrm{x}+1)$ and resemblance based on the Bray - Curtis similarity index. The SIMPROF technique (SIMilarity PROfile) was used to test for structure in data to organize the significant groups. When the significant groups were organized by SIMPROF, the MDS analysis (Non-metric Multi Dimensional Scaling analysis) was used to produce 2D graphs in order to visualize the pattern. Two-way ANOSIM (ANalysis Of SIMilarity) was used to test the significant similarity in nematode assemblage composition between groups of samples. The SIMPER analysis (SIMilarity PERcentages) was applied for identifying the taxa that are responsible for similarities and dissimilarities between seasons in each station. It examines the contribution of each taxon to the average Bray-Curtis dissimilarity between groups of samples. It also determines the contribution to similarity within a group (Clarke and Warwick, 2001).

\section{Results}

\subsection{The distribution of nematode communi- ties analysed by SIMPROF, MDS and ANOSIM}

The result of the SIMPROF analysis showed that nematode communities in all stations were not distinguished between dry and wet season. The dash line indicates the significant group (Figure 2). A multidimensional scaling (MDS) demonstrated that the nematode communities (Figure 3) showed in general not much difference between the dry and the wet season. ECT1 formed the main exception. 
The mouth stations sampled in the dry season were subdivided in two main groups: a group of sandy stations with high percentage of sand including ECT1, ECD1, EBL1, EHL1, ECH1, EDA1, and a group of silty sand stations with the stations ETD1, ECC1.
The two way ANOSIM analyses with station (estuary) and season as factors however found a Global R test for the seasonal factor of 0.94 and a significance level of $0.1 \%$ while the Global $\mathrm{R}$ test for the estuarine factor was 0.98 and the significance level $0.01 \%$.

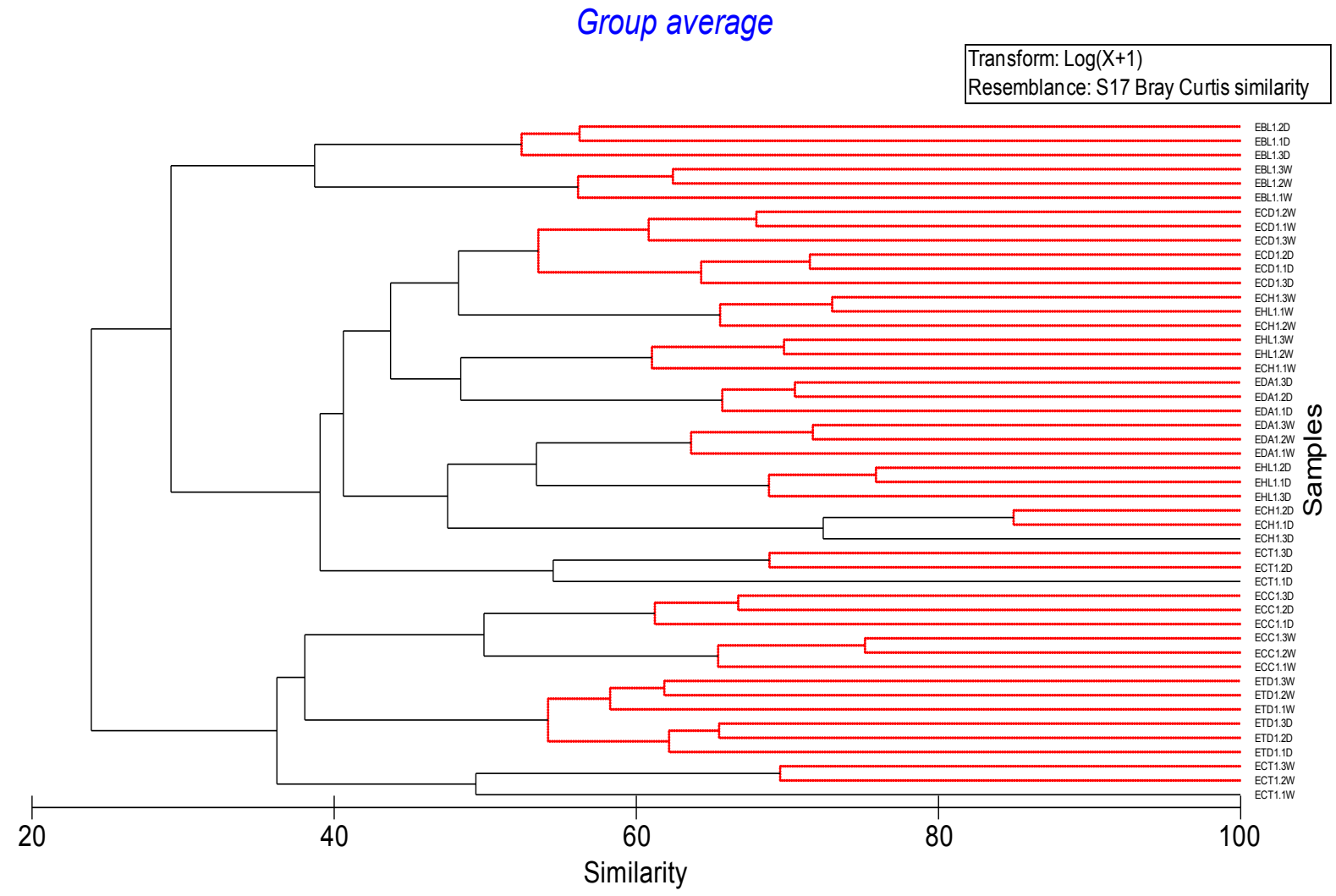

Figure 2. The SIMPROF classify the nematode communities in all stations between dry season (D) and wet sea$\operatorname{son}(\mathbf{W})$

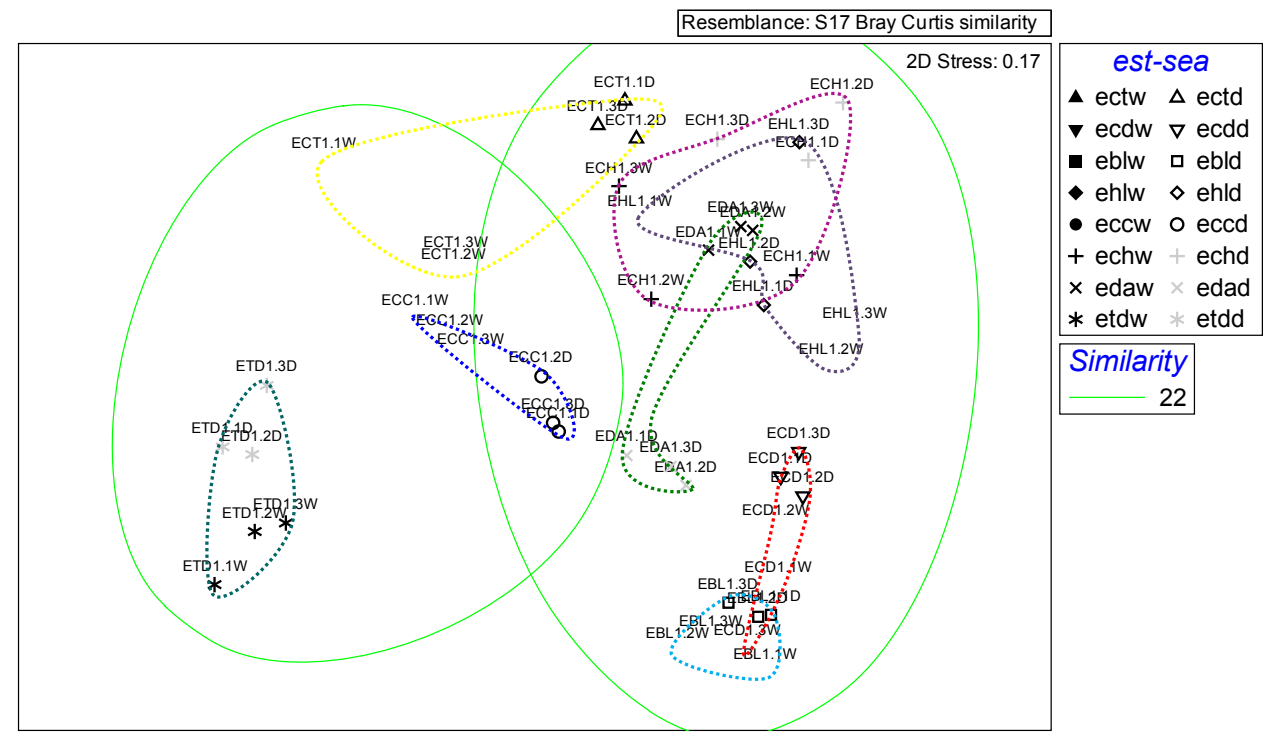

Figure 3. The MDS of nematode communities at 8 stations in dry season (D) and wet season (W) with the $22 \%$ similarities indicated in green and the stations for both seasons encircled in dashed line

\subsection{The composition of nematode communi- ties in dry and wet season}

A SIMPER analysis showed the highest dissimilarity (>80\%) between both seasons in ECT1. In the wet sea- son, this station showed a close relationship with the stations ECC1 and ETD1, whereas in the dry season it clustered with the remaining stations as shown in Figure 2. Also the stations EHL1, ECH1 and EDA1 still showed a relatively high dissimilarity $(>70 \%)$ between both 
seasons but they remained within the same large cluster group (Table 1).

Figure 4 shows the dominant genera and of which some showed important changes over the seasons. It illustrates the dominance of Desmodora and/or Oncholaimellus in the sand stations, whereas Parodontophora and Halalaimus (among others) were characteristic for the silty sand group.

Desmodora occurred in high abundances at EBL1 (55.2\%) and ECD1 (68.07\%) during the wet season and only reduced slightly their abundance in the dry season (at EBL1 49.41\% and at ECD1 36.13\%). The genus was also abundant in station EDA1, ECT1, EHL1 and ECC1 but here they increased in percentage from respectively $4.10 \%, 6.75 \%, 2.56 \%$ and $2.64 \%$ in the wet season to $20.81 \%, 14.32 \%, 11.83 \%$ and $13.07 \%$ in the dry season. In ECH1 there was a slight decrease in abundance from the wet to the dry season, while abundances remained very low for both seasons in ETD1.

Oncholaimellus dominated station EDA1 with $28 \%$ in the wet season but was also highly dominant in EHL1 (42.1\%) and ECH1 (50.7\%) although in the dry season. However this genus reduced highly in abundance to (nearly absent) in all three stations for the other season.

Parodontophora was mostly very low or absent in all the sand stations. It increased in abundance from the wet to the dry season in the silty station ETD1. In the stations ECC1 and ECT1 the genus increased from $0.53 \%$ to $6.52 \%$ and from $2.37 \%$ to $13.17 \%$ explaining the change in clustering of the last station between both seasons.

A similar pattern as for Parodontophora was noticed for Halalaimus, which was a typical genus for the silty sand, but the genus decreased in abundance (15.96 to $39.03 \%$ ) from the dry to the wet season in station ETD1. However it appeared just like Parodontophora in station ECT1 in the wet season with $4.23 \%$, while it was almost absent in the dry season.

The SIMPER analysis was performed per station and per season to identify the degree of dissimilarity and the responsible genera between seasons in each station. The average seasonal dissimilarities in each station range from $42.11 \%$ to $80.82 \%$. Several genera were identified as responsible for the dissimilarity between two seasons at each station.

In station ECT1 that showed the highest average dissimilarity percentage $(80.82 \%)$ between both seasons, the genera Parodontophora, Eumorpholaimus and Monhystera were very abundant in the wet season but almost absent in the dry season. Other genera became also less abundant in the dry season such as Elzalia, Halalaimus and Desmodora while the genera Rhynchonema increased. Also station ECH1 showed a high average dissimilarity (80.43\%), mainly because densities of Oncholaimellus, Daptonema, Sphaerotheristus and Microlaimus increased in the dry season whereas the densities of Theristus, Metachromadora, Paracanthonchus and Oncholaimus, decreased. Some other stations had slightly lower dissimilarity such as EHL1 (78.68\%) and EDA1 $(73.3 \%)$. These stations had some common genera that caused a difference between the dry and wet season such as Oncholaimellus, Desmodora, Theristus, Trefusia and Paracanthonchus in which Desmodora and Paracanthonchus increased from the wet season to dry season, while the others decreased.

The station ECC1 was also still quite different between seasons $(63.37 \%)$. The present communities were altered by the replacement of dominant genera, especially Theristus, Desmodora and Thalassomonhystera, which increase from the wet to the dry season while Terschellingia and Microlaimus changed in the opposite direction.

Table 1. The SIMPER analysis showing the total average dissimilarity for each station between dry season and wet season, the responsible genera and their contribution to the average dissimilarity (Av. Diss.)

ECT1: Average dissimilarity $80.82 \%$

GENERA
Parodontophora
Eumorpholaimus
Monhystera
Elzalia
Daptonema
Desmodora
Halalaimus
Rhynchonema

Rhynchonema

AV. D

EBL1: Average dissimilarity $42.11 \%$

GENERA
Desmodora
Microlaimus
Hypodontolaim
Oncholaimus
Theristus
Molgolaimus
Rhinema
Onyx

ECD1: Average dissimilarity 59.21\%

$\begin{array}{rlr}\text { DISS. } & \text { GENERA } & \text { AV. DISS. } \\ 8.66 & \text { Desmodora } & 29.56 \\ 7.92 & \text { Omicronema } & 7.07 \\ 7.80 & \text { Rhynchonema } & 4.43 \\ 6.34 & \text { Sphaerotheristus } & 4.12 \\ 5.21 & \text { Theristus } & 2.23 \\ 3.76 & \text { Daptonema } & 1.97 \\ 3.39 & \text { Oncholaimus } & 1.31 \\ 3.13 & \text { Parodontophora } & 0.88\end{array}$

ECC1: Average dissimilarity $63.37 \%$

$\begin{array}{rlr}\text { AV. DISS. } & \text { GENERA } & \text { AV. DISS. } \\ 7.16 & \text { Terschellingia } & 8.23 \\ 3.71 & \text { Theristus } & 7.52 \\ 3.09 & \text { Desmodora } & 6.75 \\ 2.75 & \text { Microlaimus } & 5.15 \\ 2.44 & \text { Thalassomonhystera } & 4.38 \\ 1.69 & \text { Metachromadora } & 4.10 \\ 1.61 & \text { Parodontophora } & 2.09 \\ 1.37 & \text { Ptycholaimellus } & 2.07\end{array}$


ECH1: Average dissimilarity $80.43 \%$

GENERA
Oncholaimellus

Daptonema

Sphaerotheristus

Theristus

Microlaimus

Metachromadora

Paracanthonchus

Oncholaimus

\section{AV. DI}

36.64 Oncholaimellus

7.09 Daptonema

4.79 Omicronema

4.65 Desmodora

2.90 Trefusia

2.20 Paracanthonchus

2.03 Viscosia

1.94 Theristus
24.52

7.72

6.16

5.68

5.42

4.26

3.37

3.00

EDA1: Average dissimilarity $\mathbf{7 3 . 3 0 \%}$

GENERA
Thalassomonhyster
Desmodora
Oncholaimellus
Trefusia
Theristus
Xyala
Paracanthonchus
Endeolophos

AV.

ETD1: Average dissimilarity 59.93\%

$\begin{array}{rlr}\text { DISS. } & \text { GENERA } & \text { AV. DISS. } \\ 20.59 & \text { Leptolaimus } & 12.52 \\ 13.14 & \text { Halalaimus } & 10.63 \\ 9.09 & \text { Thalassomonhystera } & 5.14 \\ 5.91 & \text { Parodontophora } & 4.80 \\ 2.44 & \text { Elzalia } & 2.79 \\ 1.87 & \text { Haliplectus } & 2.5 \\ 1.83 & \text { Leptolaimoides } & 2.00 \\ 1.63 & \text { Anoplostoma } & 1.64\end{array}$

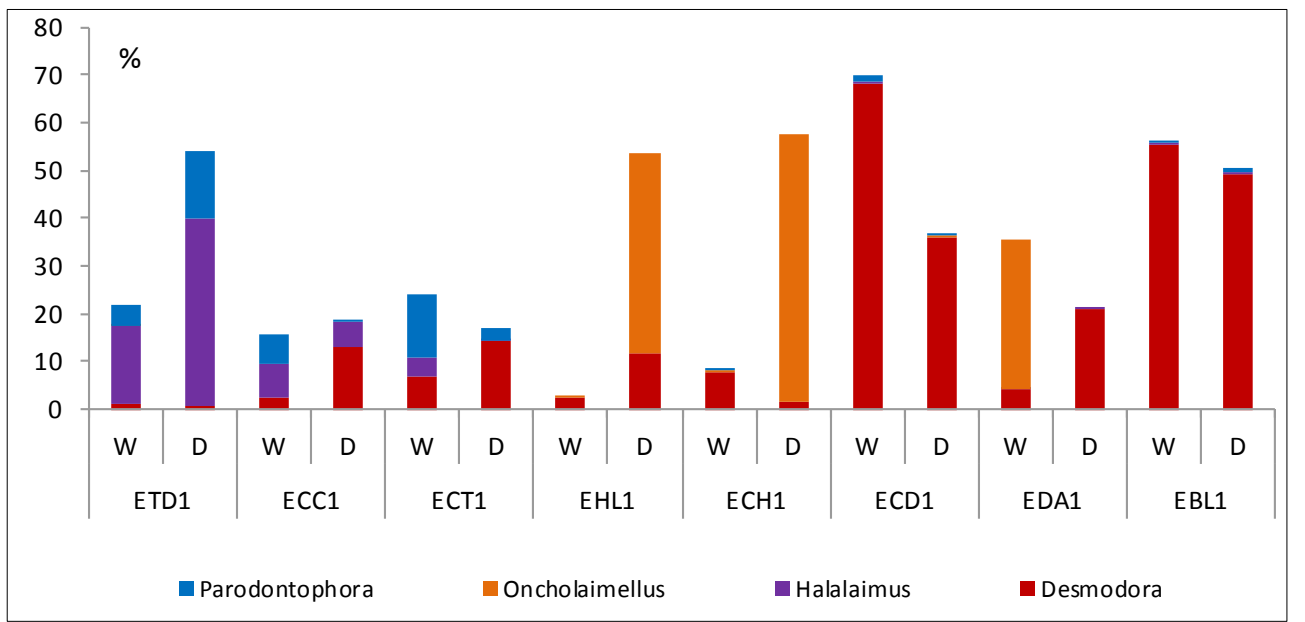

Figure 4. Relative abundance of dominant genera in two seasons at the eight estuarine stations

The total average dissimilarity in station ETD1 was $59.93 \%$, which was mainly caused by the increase of Halalaimus, Parodontophora, Elzalia and Anoplostoma from the wet to the dry season whereas Leptolaimus, Thalassomohystera, Haliplectus and Leptolaimoides showed the opposite pattern.

The lowest dissimilarities between seasons were found at two stations: EBL1 (42.11\%) and ECD1 (59.21\%). They were both dominated in each season by Desmodora, which only showed a slight decrease from the wet to the dry season. Theristus showed a similar pattern while Oncholaimus showed an opposite tendency.

\section{Discussion}

The MDS demonstrated the Mekong nematode communities showed a distribution pattern based primarily on the sediment characteristics much more than on seasonal variation. All silty sand stations were classified in one group with high similarities that separated them from the remaining sand stations except for station ECT1, which separated over the seasons between both sediment groups.
Each station in the sandy group was also clustered in the same group although some overlap between stations from this group appeared. This is similar to the study of Eskin and Coull (1987) who studied meiobenthic nematode populations in two stations, respectively with sand and mud, over three years of time series. They found that the year-to-year variability was not great and was dissimilar at both sites. This study showed that the mud species were distinctly more seasonal while the sand community lacked seasonality. The seasonal prominent pattern in the mud station was thought to be controlled by predation mechanisms whereas hydrodynamic activity is proposed as the mechanism maintaining the community at the sand site. Possibly this is also the case in our study since the silt station ECT1 showed the highest variation over time.

Indeed, the genera Desmodora and Oncholaimellus dominated with high percentages in the sandy stations (EBL1, EDA1, ECD1, ECH1 and EHL1) while Parodontophora and Halalaimus dominated in the silty sand stations (ETD1, ECC1). The station ECT1 was a transitory station since Parodontophora, Halalaimus and Desmodora all share high abundances. Those dominant genera influ- 
enced a lot the trend for changes in nematode communities on a temporal scale or spatial scale.

As found from SIMPER analysis, the larger dissimilarities for the spatial scale compared to the temporal scale was very recognizable in the stations ETD1, ECC1 and also EBL1 and ECD1. In those stations, the percentage contribution and average abundance of genera within each station between seasons was much less than between stations. It points to the fact that spatial environmental gradients in granulometry are more important than seasonal variation in environmental characters for structuring nematode community structure. It may be caused by the climate in tropical areas that only varies in precipitation between the dry and the wet season.

\section{Conclusion}

Therefore, it can be concluded that the seasonality in the Mekong estuarine system does not strongly affect the nematode communities' distribution pattern. The spatial variations in this estuarine area have an influence that is larger than seasonal factors. It may be due to the tropical climate that the nematode communities show more continuous cycle of reproduction.

\section{Acknowledgement}

This work was funded by VLIR-UOS, Belgium. The authors are grateful to Mr Dirk Van Gansbeke, Ghent University, for his sampling guidance and sediment analyses. The assistance in nematode sampling and processing by Nguyen V. Sinh and Tran T. Ngoc from Institute of Tropical Biology, Vietnam Academy of Science and Technology, is also acknowledged.

\section{References}

[1] Alongi D.M. 1987. Intertidal zonation and seasonality of meiobenthos in tropical mangrove estuaries. Marine Biology 95: 447-458

[2] Eskin, R.A., Coull, B.C. 1987. Seasonal and threeyear variability of meiobenthic nematode populations at two estuarine sites. Marine Ecological Progress Series 41: 295-303

[3] Heip, C., Vincx, M., Vranken G. 1985. The ecology of marine nematodes. Oceanography and Marine Biology: An Annual Review 23: 399-489

[4] Hodda, M., Nicholas, W.L. 1986. Nematode diversity and industrial pollution in the Hunter River Estuary, NSW, Australia. Marine Pollution Bulletin 17: 251-255

[5] Hodda M., Nicholas W.L. 1990. Production of meiofauna in an Australian estuary. Wetland 9: p.41-48

[6] Li, J., Vincx, M. 1993. The temporal variation of intertidal nematodes in the Westerschelde, I. the importance of estuarine gradient. Netherland Journal of Aquatic Ecology 27: 319-326

[7] Platt, H.M., Warwick, R.M. 1983. Free-living marine nematodes. Part I. British Enoplids. Cambridge, Cambridge University Press, 307 pp.

[8] Platt, H.M., Warwick, R.M. 1988. Free-living marine nematodes. Part II. British Chromadorids. Cambridge, Cambridge University Press, 502 pp.

[9] Tietjen J. H. (1969) The ecology of shallow water meiofauna in two New England estuaries. Oecologia 2: $251-291$

[10] Warwick, R.M., Platt H.M., Somerfield, P. J. 1988. Free living marine nematodes. Part III. Monhysterids. Cambridge, Cambridge University Press, 296 pp. 